\title{
Physico-chemical properties, probiotic stability and sensory characteristics of Lactobacillus plantarum S20 - supplemented passion fruit (Passiflora edulis f. flavicarpa Deg.) juice powder
}

\author{
*Lascano, R.A., Gan, M.G.L.D., Sulabo, A.S.L., Santiago, D.M.O., Ancheta, L.B. and \\ Zubia, C.S.
}

Institute of Food Science and Technology, College of Agriculture and Food Science, University of the Philippines Los Baños, Laguna, Philippines. 4031

\section{Article history:}

Received: 18 August 2019

Received in revised form: 13

September 2019

Accepted: 30 September 2019

Available Online: 7 October 2019

\section{Keywords:}

Probiotics,

Lactobacillus plantarum S20, Passion fruit

\section{DOI:}

https://doi.org/10.26656/fr.2017.4(2).295

\begin{abstract}
The study aimed to develop a non-dairy-based probiotic-supplemented product using an underutilized crop in the Philippines such as the yellow passion fruit (Passiflora edulis $\mathrm{f}$. flavicarpa Deg.). The physico-chemical properties (moisture content, water activity, $\mathrm{pH}$, and total soluble solids), probiotics stability at different storage temperatures $\left(4^{\circ} \mathrm{C}, 25^{\circ} \mathrm{C}\right.$, and $37^{\circ} \mathrm{C}$ ), and the sensory characteristics of Lactobacillus plantarum S20-supplemented passion fruit juice powder was evaluated. Passion fruit juice powder and L. plantarum S20 were first prepared using low-temperature spray drying utilizing maltodextrin as a carrier, with yield as $42.97 \%$ and $21.17 \%$, respectively. Spray drying of probiotics culture also resulted in $42.68 \% \log$ survivability. The formulated juice powder had a final moisture content of $1.729 \pm 0.38 \%$ and water activity of $0.398 \pm 0.0051$, and with recommended dilution with water, had a final $\mathrm{pH}$ and total soluble solids of $3.40 \pm 0.10$ and $12.00 \pm 0.00^{\circ}$ Brix, respectively. Results also showed that storage of the formulated juice powder at $4^{\circ} \mathrm{C}$ yielded the highest probiotic stability, maintaining a viable log count of 4.27 per g, while storage at $37^{\circ} \mathrm{C}$ showed no microbial growth. Sensory evaluation of probioticsupplemented passion fruit juice against a non-probiotic-supplemented one revealed significant difference in terms of color, sweetness, and sourness, while no significant difference was observed in terms of aroma, mouthfeel, and general acceptability.
\end{abstract}

\section{Introduction}

Probiotics are live beneficial microorganisms which, when taken in adequate amounts, offer health benefits beyond normal nutrition (Song et al., 2012). For a food product to be considered probiotic, $10^{6}-10^{7} \mathrm{CFU} / \mathrm{g}$ of the probiotic culture must be maintained until the end of the product's shelf life (Goderska, 2012). Probiotic food products are usually seen in the form of dairy products such as milk, cheese, and yoghurt which might confer a problem to individuals who are lactose intolerant. Moreover, vegetarianism is becoming prevalent these days. Non-dairy probiotic food products are acceptable alternatives for individuals who are either vegetarians or lactose intolerant (Lee and Salminen, 2009). The production of probiotic food requires a starter culture. Initially, commercial starter cultures are present in a liquid form. This is inconvenient because of the high costs utilized in bulk culture preparation and the risks of bacteriophage infection (Desmond et al., 2002). Because of the recent advancements made in biotechnology, concentrated starter cultures in frozen and freeze-dried forms were made available. Spray drying has been extensively used in the production of powdered foods. Spray drying addresses the problems involved in the storage, maintenance, and handling of liquid cultures. This method uses high temperatures, thereby instantly producing the powdered product as it is dried (Goderksa, 2012).

Passion fruit (Passiflora edulis) is a perennial crop which grows mostly as a vine with a shallow root system, growing up to a length range of 15-20 feet. Its leaves are trilobate, long and deep green, with a glossy upper surface and matte on its lower surface. The fruit is circular or oval shaped and is filled with membranous sacs containing the seeds. It is also filled with aril (or pulp) and juice. Passion fruits are mostly harvested in the tropical and sub-tropical parts of the world. There are an estimated 500 species of the genus Passiflora in the family Passifloraceae, with two species gaining commercial importance: the standard yellow (Passiflora edulis f. flavicarpa Deg.) and the purple (Passiflora edulis f. edulis). The yellow passion fruit is more acidic, 
with a $\mathrm{pH}$ of 2.8 while the purple passion fruit has a $\mathrm{pH}$ of 4.2. In terms of starch content, the former has $0.06 \%$ starch, while the latter has $0.74 \%$ starch. The amylose content of the yellow variety $(8.7 \%)$ is also comparatively higher than the purple one $(5.8 \%)$ (Zas and John, 2016). The purple passion fruit is mainly grown for the processing of juice due to its desirable and unique flavor. The flavor could be attributed to the several aromatic compounds present which deteriorates with high temperatures (Strohalm et al., 2007). Passion fruit is considered as underutilized and is a commonly neglected crop in the Philippines. Processing this fruit into value-added products will boost its economic value. Consequently, it will also boost utilization and further production studies.

In this study, spray drying would be used as the drying method to convert the microbial culture ( $L$. plantarum S20) and passion fruit (Passiflora edulis $\mathrm{f}$. flavicarpa) into a powdered form. This study aims to test the stability of spray dried L. plantarum S20 on passion fruit juice powder. Specifically, the study aimed to: (1) determine the viability of $L$. plantarum S20 after spray drying; (2) determine the drying yield of $L$. plantarum S20 cells and passion fruit slurry after their respective spray drying processes; (3) test for certain physicochemical properties (water activity, moisture content, total soluble solids, and $\mathrm{pH}$ ) of the passion fruit juice powder incorporated with spray dried L. plantarum S20; (4) determine the effect of storage conditions with respect to varying temperatures $\left(4,25\right.$ and $\left.37^{\circ} \mathrm{C}\right)$ on the survivability of $L$. plantarum $\mathrm{S} 20$ incorporated in passion fruit powder; and (5) conduct a sensory test that would compare the attributes between two treatments: passion fruit juice with and without spray dried $L$. plantarum S20 cells.

\section{Materials and methods}

\subsection{Microbial culture}

Pure culture of $L$. plantarum S20 was obtained from University of the Philippines Los Baños - National Institute of Molecular Biology and Biotechnology (UPLB-BIOTECH). The microbial culture was grown in de Man, Rogosa, and Sharpe (MRS) broth added with $30 \%(\mathrm{v} / \mathrm{v})$ glycerol and stored at a temperature of $4^{\circ} \mathrm{C}$.

\subsection{Spray drying of microbial culture}

L. plantarum S20 culture was incubated at $37^{\circ} \mathrm{C}$ for 18 hours in MRS Broth to achieve a targeted $10^{11} \mathrm{CFU} / \mathrm{g}$ microbial cell count. The cell suspension was aseptically transferred to centrifuge tubes and was subjected to centrifugation at $4300 \mathrm{x} g$ for $15 \mathrm{mins}$ at $4^{\circ} \mathrm{C}$. Next, $1 \mathrm{ml}$ of $0.85 \%$ saline solution was used to wash the remaining filtrate twice. Afterward, $30 \%(\mathrm{v} / \mathrm{v})$ of $50 \%$ maltodextrin solution was added as the encapsulating agent. The spray drying of the cell suspension with maltodextrin and saline solution was done using an industrial-scale model YK-100 Low-Temperature Spray Dryer (True Ten, Taiwan) at the Fermentation Engineering Pilot Plant of UPLB-BIOTECH. The spray dryer operates with a single fluid atomizer and a co-current regime at a flow rate of $0.67 \mathrm{~L} / \mathrm{hr}$. The prepared solution was fed into a spray dryer at an inlet temperature of $42^{\circ} \mathrm{C}$ and an outlet temperature of $35^{\circ} \mathrm{C}$. The resulting powder was collected at the bottom of the cyclone separator and stored in sterilized vials. The drying yield of the spray dried microbial culture was computed using Equation 1:

drying yield (\%) $=\frac{\text { weight of spray dried product, } g}{\text { weight of feed solution, } g} \times 100$

\subsection{Determination of viability of spray dried cells}

Standard microbial enumeration using MRS agar was done to determine the viability of the cells. Percent $\log$ survivability of the microbial cells was then computed using Equation 2, with No = cell count before spray drying, and $\mathrm{N}=$ cell count after spray drying.

$$
\% \log \text { survivability }=\frac{\log (\mathrm{N})}{\log (\mathrm{No})} \times 100
$$

\subsection{Spray drying of passion fruit}

Ripe yellow passion fruits (Passiflora edulis $\mathrm{f}$. flavicarpa Deg.) were obtained from a local market in Lucban, Quezon Province, Philippines. The passion fruits were processed into puree using standard protocols. The passion fruit slurry was diluted with water in a 1:3 ratio (passion fruit puree: water). The resulting solution was added with $25 \%(\mathrm{w} / \mathrm{v})$ of $50 \%$ maltodextrin. Next, the slurry was fed into an industrial-scale model YK-100 Low-Temperature Spray Dryer (True Ten, Taiwan) at the Fermentation Engineering Pilot Plant of UPLB-BIOTECH. The spray dryer operates with a single fluid atomizer and a co-current regime at a flow rate of $0.67 \mathrm{~L} / \mathrm{h}$. The inlet temperature used was $55^{\circ} \mathrm{C}$ and an outlet temperature of $40^{\circ} \mathrm{C}$. The resulting powder was collected at the bottom of the cyclone and stored in a sterilized jar. Drying yield was computed using Equation 1.

\subsection{Formulation of passion fruit juice powder with spray dried Lactobacillus plantarum $\mathbf{S 2 0}$}

The formulation of the powder mix was based on the experimental trials which when diluted with $100 \mathrm{~mL}$ of distilled water would yield total soluble solid (TSS) of 12.00 and $\mathrm{pH}$ between 3.2 to 3.5. The formulation included $2.5 \mathrm{~g}$ of passion fruit powder, $9.9 \mathrm{~g}$ of sugar, and $0.05 \mathrm{~g}$ of citric acid. The spray dried probiotic culture was added equivalent to $10 \%$ to the total weight 
of the powder solids.

\subsection{Probiotic stability at different storage temperatures}

The powdered juice added with spray dried $L$. plantarum cells were stored in sealed and sterilized polypropylene bags. Stability of the bacteria in the passion fruit juice powder was tested in different storage temperatures: $4^{\circ} \mathrm{C}, 25^{\circ} \mathrm{C}$ and $37^{\circ} \mathrm{C}$. Standard microbial enumeration in MRS agar was done every week for four consecutive weeks.

\subsection{Physico-chemical analysis of the formulated juice powder}

The resulting passion fruit juice powder incorporated with spray dried $L$. plantarum was tested for the following parameters: (1) $\mathrm{pH}$ using Milwaukee $\mathrm{pH} 600$ pocket-size pH pen, (2) Total Soluble Solids (TSS) using ATAGO Master-M (0-33\%) hand-held refractometer, (3) moisture content using oven drying method (AOAC, 2007), and (4) water activity using Novasina LabSwift table-top water activity meter. All measurements were done in triplicate.

\subsection{Sensory evaluation}

The intensity of different sensory attributes namely, color, aroma, mouthfeel, sweetness, sourness, as well as the general acceptability of the samples was determined by quality scoring using a $15-\mathrm{cm}$ line scale. These attributes were evaluated by 25 selected panelists who already took basic courses in sensory evaluation of food. The suggested number of medium-trained panelist for quality scoring is $8-12$, or five (5) highly trained panelist (Kilcast, 2010). The number of panelists was increased to 25 to make the responses approach normality based on the law of large numbers. For the statistical analysis, randomized complete block design (RCBD) was used as the experimental design. Analysis of variance (ANOVA) was analyzed using the Statistical Tools for Agricultural Research (STAR) Software Version 2.0.1 (IRRI - BBI, 2019). The significance of differences was defined as $P$ $<0.05$.

\section{Results and discussion}

\subsection{Spray drying yield}

The drying yield percentage of the passion fruit and L. plantarum cells is shown in Table 1 . The liquid passion fruit was incorporated with $25 \%$ maltodextrin while the probiotic cells were incorporated with $30 \%$ maltodextrin. The amount of maltodextrin added to the inlet suspension is relatively close to the drying yield percentage acquired in $L$. plantarum cells. Since the passion fruit slurry is quite sticky in nature, more particles adhered to the encapsulating agent, attaining a higher drying yield.

Table 1. Spray drying yield of microbial cells and passion fruit slurry.

\begin{tabular}{lc}
\hline \multicolumn{1}{c}{ Sample } & Drying Yield, \% \\
\hline Passion Fruit & 42.97 \\
L. plantarum cells & 21.17 \\
\hline
\end{tabular}

\subsection{Viability of Lactobacillus plantarum S20 after spray} drying

The logarithmic survivability of the L. plantarum S20 cells after spray drying is shown in Table 2. Spray drying uses high temperatures which may denature proteins, making the microorganism unable to perform its metabolic processes properly. Moreover, the high pressure utilized in spray drying could have damaged the cells resulting in low cell viability. However, the presence of surviving cells suggests that the carrier, maltodextrin, offered a certain degree of protection for the cells. Maltodextrin, and combinations with other wall material such as inulin and oligofructose, had shown satisfactory recovery of probiotic cells after spray drying, resulting in microbial counts of up to $10^{10} \mathrm{CFU} / \mathrm{g}$ (Paim et al., 2016).

Table 2. Survivability L. plantarum S20 cells after spray drying.

\begin{tabular}{lc}
\hline \multicolumn{1}{c}{ Parameter } & Value \\
\hline Initial Cell Count, $\log$ CFU/mL & 11.2 \\
Final Cell Count, $\log$ CFU/mL & 4.78 \\
Log Survivability, $\%$ & 42.7 \\
\hline
\end{tabular}

\subsection{Physico-chemical properties of the passion fruit juice powder with probiotics.}

Table 3 summarizes the physicochemical properties of the formulated juice powder. The average $\mathrm{pH}$ of the formulated passion fruit juice is 3.4. With this $\mathrm{pH}$ value, the probiotic bacteria $L$. plantarum would still be able to proliferate since it could tolerate lower $\mathrm{pH}$ levels of up to 3.2 (Zago et al., 2011), with some studies showing growth of L. plantarum at a $\mathrm{pH}$ as low as 2.5 (Guo et al., 2017). The $\mathrm{pH}$ of the raw yellow passion fruit (Passiflora edulis f. flavicarpa Deg) is 2.8 (Zas and John, 2016). The observed water activity of the formulated juice powder was 0.398 . Water activity is a measure of stability in foods since it indicates the amount of available water for microbial growth and chemical reactions. For most food systems, the critical water activity below which no microorganisms can grow commonly ranges from $0.6-0.7$, with critical water activity for growth of pathogenic bacteria set at 0.85 0.86 . In relation, the water activity of the powdered product is far from the critical water activity, hence it could be a measure to state that the final product is safe in terms of the growth of pathogenic bacteria. However, 
Table 3. Physicochemical properties of passion fruit juice powder with spray dried L. plantarum S20.

\begin{tabular}{lcccc}
\hline \multirow{2}{*}{ Sample } & \multicolumn{3}{c}{ Physicochemical Properties } \\
\cline { 2 - 5 } & $\mathrm{pH}^{*}$ & $\mathrm{TSS},{ }^{\circ}$ Brix* & \% & Water Activity $\left(\mathrm{A}_{\mathrm{w}}\right)$ \\
\hline Passion fruit juice with spray dried L. plantarum S20 & $3.40 \pm 0.1$ & $12.00 \pm 0.0$ & $1.729 \pm 0.38$ & $0.398 \pm 0.0051$ \\
Passion fruit juice without spray dried L. plantarum S20 & $3.32 \pm 0.2$ & $12.00 \pm 0.0$ & $1.690 \pm 0.51$ & $0.385 \pm 0.0040$ \\
\hline
\end{tabular}

* Preparations with $10 \%$ solution $(\mathrm{w} / \mathrm{v})$

since the water activity value is low, it plays a factor in the decrease in the growth of spray dried L. plantarum S20 after spray drying and storage. Moisture content is the amount of free water in each system. Knowledge of moisture content is important because it is a factor in dictating product stability during storage. Moreover, low moisture content is economical since the weight of water contributes to the total weight of the product. Less moisture could make transportation costs of products cheaper for manufacturers.

\subsection{Probiotic stability at different storage temperatures}

The viability of the spray dried probiotic cells in passion fruit juice powder was evaluated in different storage temperatures: $4^{\circ} \mathrm{C}, 25^{\circ} \mathrm{C}$, and $37^{\circ} \mathrm{C}$. The $\log$ reduction of the microbial cells per week at varying temperatures are listed in Table 4 . The passion fruit added with spray dried L. plantarum S20 placed at $4^{\circ} \mathrm{C}$ had the best performance among the treatments, maintaining microbial count of up to $4.27 \log \mathrm{CFU} / \mathrm{gram}$ or $91.63 \% \log$ survivability after the test period. Moreover, it was observed that the powdered product stored at $25^{\circ} \mathrm{C}$ had growth in the first two weeks but stopped growing starting from the third week, while it was noted that the product stored at $37^{\circ} \mathrm{C}$ showed no observed growth after one week of storage. Possible reasons behind the cease in growth of L. plantarum are the presence of light during storage and the lack of pretreatment prior to spray drying. Studies have been conducted wherein they were able to successfully maintain probiotic cell count even at room temperature. The probiotic powders were stored at room temperature, but light source was absent (Barbosa et al., 2012) and sub-lethal thermal shock was applied to the cells prior to spray drying (Anekella and Orsat, 2013). Meanwhile, having the combination of heat and low water activity resulted in the very poor performance observed in the cell growth at $37^{\circ} \mathrm{C}$.
Table 4. Microbial change in passion fruit juice powder at 4 , 25 and $37^{\circ} \mathrm{C}$ storage temperatures.

\begin{tabular}{cccc}
\hline $\begin{array}{c}\text { Storage } \\
\text { Temperature } \\
\left({ }^{\circ} \mathrm{C}\right)\end{array}$ & $\begin{array}{c}\text { Time } \\
(\text { Weeks })\end{array}$ & $\begin{array}{c}\text { Cell Count } \\
(\text { Log CFU/g) }\end{array}$ & $\begin{array}{c}\text { Log Survivability } \\
(\%)\end{array}$ \\
\hline & 0 & 4.66 & --- \\
4 & 1 & 4.58 & 98.28 \\
& 2 & 4.46 & 95.71 \\
& 3 & 4.29 & 92.06 \\
& 4 & 4.27 & 91.63 \\
\hline & 0 & 4.66 & --- \\
25 & 1 & 3.94 & 84.55 \\
& 2 & 1.91 & 40.99 \\
& 3 & 0 & 0 \\
& 4 & 0 & 0 \\
\hline \multirow{3}{*}{37} & 0 & 4.66 & --- \\
& 1 & 0 & 0 \\
& 2 & 0 & 0 \\
& 3 & 0 & 0 \\
\hline
\end{tabular}

\subsection{Sensory evaluation}

Sensory evaluation is a tool used to determine human responses to food while minimizing biases and other information that influences perceptions (Lawless and Hildegarde, 2010). In this study, two treatments were tested: passion fruit juice without spray dried $L$. plantarum S20 and passion fruit juice with spray dried $L$. plantarum S20 based on six attributes. These attributes are color, aroma, mouthfeel, sweetness, sourness, and general acceptability. The sensory means scores of the two treatments are displayed in Table 5.

\subsubsection{Aroma and mouthfeel}

No significant difference was observed between the two preparations in terms of aroma and mouthfeel, suggesting that the added spray dried probiotic culture does not affect these sensory attributes. This can also be an indication that the incorporated microorganisms are

Table 5. Comparison of the sensory attributes of passion fruit juice with and without spray dried L. plantarum S20.

\begin{tabular}{lllllll}
\hline \multicolumn{1}{c}{ Treatments } & Aroma & Color & Mouthfeel & Sweetness & Sourness General Acceptability \\
\hline Passion fruit juice without spray dried L. plantarum S20 & $8.41^{\mathrm{a}}$ & $4.13^{\mathrm{b}}$ & $11.78^{\mathrm{a}}$ & $8.25^{\mathrm{a}}$ & $7.67^{\mathrm{a}}$ & $10.16^{\mathrm{a}}$ \\
Passion fruit juice with spray dried L. plantarum S20 & $8.71^{\mathrm{a}}$ & $6.60^{\mathrm{a}}$ & $10.92^{\mathrm{a}}$ & $9.89^{\mathrm{b}}$ & $6.42^{\mathrm{b}}$ & $10.93^{\mathrm{a}}$ \\
\hline
\end{tabular}

* Means with the same letter in the same column are not significantly different from each other at $\mathrm{P}<0.05$

** Range of Scale:

Aroma: 0-weak to 15-strong; Color: 0- light to 15-dark; Mouthfeel: 0-gritty to 15-smooth; Sweetness: 0-bland to 15-sweet; Sourness: 0-weak to 15-strong; General Acceptability: 0-unacceptable to 15-Highly acceptable 
non-fermenting with limited activities due to the low water activity (Troller and Christian, 1978) of the powdered product and thus, do not produce fermentation by-products which may contribute to the overall aroma and mouthfeel. The primary aroma of the passion fruit juice can be attributed to the volatile compounds ethyl butanoate and ethyl hexanoate, which shows the highest odoriferous importance for organic passion fruit (Janzantti and Monteiro, 2014).

\subsubsection{Color}

This sensory attribute aimed to test for the lightness or darkness of the two samples. The means scores of the two treatments were significantly different from each other with the probiotic-supplemented product having a higher mean score, indicating that it is darker in color. The incorporation of the spray dried microbial cells made the color of the juice darker and opaquer which could be attributed to the added solids. The image of the juice samples applied with and without spray dried microbial cells could be seen in Figure 1.

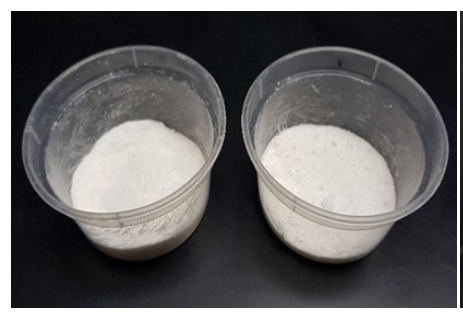

(A)

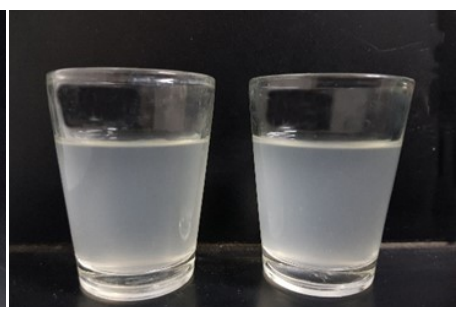

(B)
Figure 1. Color comparison of the two treatments. (A) powdered juice product; (B) prepared passion fruit juice. Per image: (left) preparation with L. plantarum S20; (right) preparation without L. plantarum S20.

\subsubsection{Sweetness}

Based on the results displayed in Table 5, the mean scores of the two treatments were significantly different from each other. The treatment incorporated with spray dried L. plantarum S20 cells turned out to be sweeter than the treatment without the spray dried cells. Maltodextrin was the encapsulating agent used during spray drying. Maltodextrin has a very low sweetness level graded as 0.05 times that of sucrose (Ashurst, 2016). Although it does not practically add sweetness to the product, maltodextrin offers a "bodying effect" or the apparent increase in the viscosity of the resulting juice drink (Kearsley and Dziedzic, 1995). For solutions with suprathreshold levels of sugar, it was observed that the more viscous solutions were perceived as sweeter (Rao, 2007).

\subsubsection{Sourness}

The two treatments were significantly different in terms of sourness. The judges perceived the treatment without added spray dried L. plantarum S20 cells to be sourer than the treatment added with spray dried cells. The addition of maltodextrin could have made the treatment added with spray dried cells sweeter, thus, masking their perception of the sourness.

\subsubsection{General acceptability}

The general acceptability accounts for the overall liking of the judges of the samples. Based on the results listed in Table 5, there was no significant difference in the general acceptability mean scores of the two treatments. Hence, the juice sample added with spray dried L. plantarum cells is comparable to regular passion fruit juice. Both treatments have mean scores that are closer to the right end of the scale, indicating that the passion fruit juice is acceptable by the judges.

\subsubsection{Correlation of sensory attributes to the general acceptability}

The attribute that greatly contributed to the final product's general acceptability was tested using the correlation analysis. The sweetness attribute had the highest correlation coefficient among other sensory attributes, followed by color, aroma, and sourness, respectively, and has the significant effect on the general acceptability, as shown by a P-value of 0.034 . Mouthfeel, on the other hand, has a negative correlation with general acceptability, indicating that the panelists perceived the juice drink with increased smoothness as less acceptable compared to the juice drink with perceived texture which may be contributed by suspended particles in the preparation. The correlation coefficient and corresponding p-values of the sensory attributes compared to the general acceptability are presented in Table 6 .

Table 6. Correlation of sensory attributes to general acceptability

\begin{tabular}{ccc}
\hline $\begin{array}{c}\text { Sensory Attribute Compared } \\
\text { to General Acceptability }\end{array}$ & $\begin{array}{c}\text { Pearson's Correlation } \\
\text { Coefficient }^{1}\end{array}$ & P-Value $^{2}$ \\
\hline Color & 0.1917 & 0.182 \\
Aroma & 0.176 & 0.221 \\
Mouthfeel & -0.0581 & 0.689 \\
Sweetness & 0.3005 & 0.034 \\
Sourness & 0.1659 & 0.25 \\
\hline
\end{tabular}

${ }^{1} \mathrm{~N}=50$ observations

${ }^{2}$ Level of significance is tested at $\mathrm{P}=0.05$.

\section{Conclusion}

This study aimed to produce a probioticsupplemented passion fruit juice powder and test the stability of L. plantarum S20 in the juice powder. Lowtemperature spray drying with maltodextrin as carrier 
resulted in powdered passion fruit juice and L. plantarum S20 powder with recovery of $42.97 \%$ and $21.17 \%$, respectively. Spray drying of probiotic culture also resulted in $42.68 \% \log$ survivability. The formulated juice powder had a final moisture content of $1.729 \pm 0.38 \%$ and water activity of $0.398 \pm 0.0051$, and with recommended dilution with water, had a final $\mathrm{pH}$ and total soluble solids of $3.40 \pm 0.10$ and $12.00 \pm 0.00^{\circ}$ Brix, respectively. The stability of $L$. plantarum in the final juice powder was evaluated at different storage temperatures $\left(4^{\circ} \mathrm{C}, 25^{\circ} \mathrm{C}\right.$ and $\left.37^{\circ} \mathrm{C}\right)$ for four weeks. Among the treatments, only the sample placed in $4^{\circ} \mathrm{C}$ yielded the highest probiotic stability, maintaining a viable $\log$ count of 4.27 per g, while storage at $37^{\circ} \mathrm{C}$ showed no microbial growth. Sensory evaluation of probiotic-supplemented passion fruit juice against a nonprobiotic-supplemented one revealed significant difference in terms of color, sweetness, and sourness, while no significant difference was observed in terms of aroma, mouthfeel, and general acceptability. For future research, it is highly recommended that pre-treatments like thermal shock be applied to the cells to maintain high cell viability. The combination of two types of probiotic cultures exhibiting synergistic effects could also be done to increase cell counts even after spray drying. During storage of the probiotic powders, the absence of light could be tested to determine whether higher cell counts would be attained. Moreover, addition of other encapsulating agents like trehalose and cornstarch could be used to test whether a higher spray drying yield and cell viability could be achieved.

\section{Conflict of Interest}

The authors declare no conflict of interest.

\section{Acknowledgments}

This research was made possible with the financial aid from the Department of Agriculture - Bureau of Agricultural Research (DA-BAR) thru the project entitled "Utilization of Neglected Underutilized Tropical Fruits for the Development of High Value Food Products" and the UPLB Basic Research Program thru the project entitled "A Model System for the Production of Non-Dairy Probiotic Products From Indigenous Food Crops Using a Standardized Lactobacillus plantarum Starter".

\section{References}

Anekella, K. and Orsat, V. (2013). Optimization of microencapsulation of probiotics in raspberry juice by spray drying. LWT - Food Science and Technology, 50(1) 17-24. https://doi.org/10.1016/ j.lwt.2012.08.003

AOAC. (2007). Official Methods of Analysis, 18th ed. Association of Official Analytical Chemist International, Gaithersburg, MD.

Ashurst, P.R. (2016). Chemistry and Technology of Soft Drinks and Fruit Juices. 3rd ed. United Kingdom: John Wiley and Sons, Ltd. https:// doi.org/10.1002/9781118634943

Barbosa, J., Borges, S. and Teixeira, P. (2016). Effect of different conditions of growth and storage on the cell counts of two lactic acid bacteria after spray drying in orange juice. MDPI, 2(8), 1-12. https:// doi.org/10.3390/beverages 2020008

Desmond, C., Stanton, C., Fitzgerald,G., Collins, K. and Ross, R.P. (2002). Environmental adaptation of probiotic lactobacilli towards improvement of performance during spray drying. International Dairy Journal, 12(2-3), 183-190. https:// doi.org/10.1016/S0958-6946(02)00040-7

Goderska, K. (2012). Different Methods of Probiotics Stabilization. In Rigobelo, E.C. (Ed.). Probiotics., p. 541-550. IntechOpen [Online E-Book]. https:// doi.org/10.5772/50313

Guo, Y., Tian, X., Huang, R., Tao, X., Shah, N., Wei, H. and Wan, C. (2017). A physiological comparative study of acid tolerance of Lactobacillus plantarum ZDY 2013 and Lactobacillus plantarum ATCC 8014 at membrane and cytoplasm levels. Annals of Microbiology, 67(10), 669-677. https:// doi.org/10.1007/s13213-017-1295-x

(IRRI - BBI) International Rice Research Institute Biometrics and Breeding Informatics. (2019). STAR - Statistical Tool for Agricultural Research. Retrieved: January 1, 2019 from http://bbi.irri.org/ products

Janzantti, N. S. and Monteiro, M. (2014). Changes in the aroma of organic passion fruit (Passiflora edulis Sims f. flavicarpa Deg.) during ripeness. $L W T$ - Food Science and Technology, 59(2), 612-620. https:// doi.org/10.1016/j.lwt.2014.07.044

Kearsley, M. W. and Dziedzic, S. Z. (Eds.). (1995). Handbook of Starch Hydrolysis Products and their Derivatives. Boston, MA: Springer. https:// doi.org/10.1007/978-1-4615-2159-4

Kilcast, D. (2010). Sensory Analysis for Food and Beverage Quality Control. Florida, USA: Woodhead Publishing, LTD. https:// doi.org/10.1533/9781845699512

Lawless, L. and Hildegarde, H. (2010). Sensory Evaluation of Food: Principles and Practices. 2nd ed. New York, USA: Springer. https:// doi.org/10.1007/978-1-4419-6488-5 
Lee, Y. and Salminen, S. (2009). Handbook of Probiotics and Prebiotics. New Jersey, USA: John Wiley \& Sons, Inc. https://doi.org/10.1002/9780470432624

Paim, D.R.S.F., Costa, S. D.O., Walter, E.H.M. and Tonon, R.V. (2016). Microencapsulation of probiotic jussara (Euterpe edulis M.) juice by spray drying. LWT - Food Science and Technology, 74, 21-25. https://doi.org/10.1016/j.lwt.2016.07.022

Rahman, S. (2007). Handbook of Food Preservation. 2nd ed. USA: CRC Press. https:// doi.org/10.1201/9781420017373

Rao, M.A. (2007). Rheological Behavior of Processed Fluid and Semisolid Foods. Boston, MA: Springer. https://doi.org/10.1007/978-0-387-70930-7_5

Strohalm, H., Dregus, M., Wahl, A. and Engel, K.H. (2007). Enantioselective analysis of secondary alcohols and their esters in purple and yellow passion fruits. Journal of Agricultural Food Chemistry, 55(25), 10339-10344. https:// doi.org/10.1021/jf072464n

Song, D., Ibrahim, S. and Hayek, S. (2012). Recent Application of Probiotics in Food and Agricultural Science. In Rigobelo, E.C. Probiotics. p. 3-25. IntechOpen. https://doi.org/10.5772/50121

Troller, J.A. and Christian, J.H.B. (1978). Water Activity and Food. New York: Academic Press, Inc. 252 p. https://doi.org/10.1016/B978-0-12-700650-5.X5001$\mathrm{X}$

Zago, M., Fornasari, M.E., Carminati, D., Burns, P., Suarez, V., Vinderola, G., Reinheimer, J., and Giraffa, G. (2011). Characterization and probiotic potential of Lactobacillus plantarum strains isolated from cheeses. Food Microbiology. 28(5), 10331040, 28, 1033-1040. https://doi.org/10.1016/ j.fm.2011.02.009

Zas, P. and John, S. (2016). Diabetes and medicinal benefits of Passiflora edulis. International Journal of Food Science, Nutrition and Dietetics, 5(2), 265269. 